\title{
基于百度街景图像的行人视角城市街道植被绿化 格局分析
}

\section{冯思远 ${ }^{1}$ 魏亚楠 ${ }^{1}$ 王振娟 ${ }^{1}$ 于新洋 $1,2,3^{*}$}

${ }^{1}$ 山东农业大学资源与环境学院, 山东泰安 $271018 ;{ }^{2}$ 中国科学院地理科学与资源研究所, 北京 $100101 ;{ }^{3}$ Tropical Research and Education Center, University of Florida, Homestead Florida, 33031, USA

摘 要 城市街道绿化植被作为城市景观的重要组成部分, 其分布格局对城市景观美学发展及行人身心健康有显著影响, 立 足行人视角准确监测街道绿植分布信息对城市规划与管理有明确的辅助作用。该文针对已有研究多采用沿天底方向垂直向下 观测的遥感影像监测地表植被而对行人视角的绿色植被分布格局研究涉及不多的现状, 基于免费获取的百度街景图像, 选取 绿植覆被典型的泰安市区为案例区，结合网络信息抓取与空间地理信息处理技术，分析百度街景图像提取侧视绿植信息的可 行性, 统计并对比其计算结果与遥感影像提取结果的关系, 以期为城市规划与管理提供辅助参考信息。网络抓取案例区 273 个样点共3 276幅百度街景图像, 利用计算机监督分类提取图像中的绿植区域; 基于空间分析模型分析街道绿色植被的分布 格局; 利用SPSS软件趋势拟合模块分析百度街景图像与遥感影像提取的植被信息的相关性。主要结果为: 百度街景图像可作 为主数据源提取城市街道的侧视绿植分布情况; 案例区不同区域植被分布指数区别较大, 空间格局差异明显; 百度街道植被 分布指数与基于遥感图像提取的10、20、50 m缓冲距离范围内植被覆盖面积呈显著正相关关系, 但两者的变化趋势并非完全 一致。百度街道植被分布结果可作为遥感监测结果的辅助信息更好地指导城市绿色景观规划与精准管理。

关键词 街景图像; 街道植被分布指数; 侧视视角; 植被格局; 监督分类

冯思远, 魏亚楠, 王振娟, 于新洋 (2020). 基于百度街景图像的行人视角城市街道植被绿化格局分析. 植物生态学报, 44, 205-213. DOI: 10.17521/ cjpe.2019.0236

\section{Pedestrian-view urban street vegetation monitoring using Baidu Street View images}

FENG Si-Yuan ${ }^{1}$, WEI Ya-Nan ${ }^{1}$, WANG Zhen-Juan ${ }^{1}$, and YU Xin-Yang ${ }^{1,2,3^{*}}$

${ }^{1}$ Department of Resources and Environment, Shandong Agricultural University, Tai'an, Shandong 271018, China; ${ }^{2}$ Institute of Geographic Sciences and Natural Resources Research, Chinese Academy of Sciences, Beijing 100101, China; and ${ }^{3}$ Tropical Research and Education Center, University of Florida, Homestead Florida, 33031, USA

\footnotetext{
Abstract

Aims The distribution pattern of green vegetation in urban streets has significant impacts on urban ecological environment and physical/mental health of local residents. Accurate detecting and monitoring of street green information is of great significance for precise urban planning and management, while there are few studies focusing on urban greenery estimation using profile image system.

Methods In this study, combining network information capturing and geospatial information analysis technology, Tai'an city was selected as the case study area. Based on the Baidu application programming interface (API), a total of 3276 Baidu Street View (BSV) images of 273 research samples were obtained and processed, and the green vegetation pixels in the image were extracted by computer supervised classification and compared with the artificial extraction results. Based on the proposed Baidu Street Vegetation Distribution Index (BSVDI), we monitored the street vegetation's distribution characteristics from the pedestrian perspective, and analyzed the streetscale vegetation distribution pattern.

Important findings The BSV image could be used as the main data source to monitor the distribution of green trees and lawns in pedestrian's perspective on the street scale. BSVDI was higher in the center, northeast and southeast of the study area than the other regions. BSVDI and remote sensing extracted vegetation covered area

收稿日期Received: 2019-09-05 接受日期Accepted: 2020-01-27

基金项目：国家自然科学基金(41877003)和“十二五”国家科技支撑计划项目(2015BAD23B0202)。Supported by the National Natural Science Foundation of China (41877003), and the "Twelfth Five-Year" National Science and Technology Support Plan Project (2015BAD23B0202).

* 通信作者Corresponding author (xyyu@yic.ac.cn)
} 
are significantly and positively correlated, with correlation coefficient of $0.76,0.63$ and 0.49 in the buffered distance of 10, 20 and $50 \mathrm{~m}$, respectively. However, the change trends of the BSVDI and remote sensing results were not completely consistent in each study site. This study implies that the combination of BSVDI and remote sensing monitoring results can better guide urban green landscape planning and precise management.

Key words street view image; street greenery index; profile view; vegetation pattern; supervised classification

Feng SY, Wei YN, Wang ZJ, Yu XY (2020). Pedestrian-view urban street vegetation monitoring using Baidu Street View images. Chinese Journal of Plant Ecology, 44, 205-213. DOI: 10.17521/cjpe.2019.0236

城市景观是自然与人工元素的复杂组合，其美 学质量直接影响城市形象和居民生活环境(吴健生 等, 2017)。随着近年来城市空气污染(王赞红和李纪 标, 2006)、热岛效应(白杨等, 2013; 王刚等, 2017; 苏嫄和包玉, 2018)加剧, 城市街道绿色植被(乔灌 木、草坪等)作为城市景观的重要组成部分(李薇, 2007; 张佳晖, 2017), 在调节气候 (任学慧等, 2006)、改善城市生态环境(李净等, 2017; 李卓等, 2017; 王静等, 2017)、涵养水源(魏冬等, 2017)、保 护生态稳定性与多样性的重要性日渐明显。基于街 道行人视角分析街道植被分布情况可为城市景观研 究及城市智能管理提供方法与信息支持。

传统的街道绿植监测多采用现场识别(Downs et al., 1977)、统计分析(van Dillen et al., 2012)、问卷 调查(Aoki et al., 1985; Klemm et al., 2015)等形式评 估街道植被绿化质量。20世纪 80 年代以来, 众多学 者基于卫星遥感获取陆面植被冠层信息(陈庆男, 1984; 王思远等, 2002; 杨志青等, 2016), 植被监测 效率大幅提高(Yang et al., 2017; Di et al., 2019), 相 关研究进展迅速。遥感图像因提取的植被信息物理 意义明显, 目前已被广泛用于城市规划与街道植被 监测分析。然而, 受制于传感器的侧摆能力及穿透 性能, 获取的遥感数据多为冠层数据, 难以形成基 于行人视角的城市街道绿植分布结果, 在有多层植 被重叠覆盖及坚直方向植被分布情况下难以准确监 测(Camacho-Cervantes et al., 2014)。另一方面, 基于 以人为本的可持续发展理念(王风江, 2004; 孙平, 2006), 城市绿地的监测与规划调整宜考虑行人的 主观感受因素, 而目前基于行人视角的绿植监测及 分析受到数据源的限制开展较少。近年来, 个人穿 戴及地面移动端激光测距仪的应用使得树木物理特 性(如胸径、树高)及生物量测量更为准确便捷(王佳 等, 2013; 张佳晖等, 2017), 已有研究应用于城市街 道植被点云生成与分析监测( 卜帆和石玉立，2017; Golombek \& Marshall, 2019; Heo et al., 2019)。目前
激光测距仪不确定因素较多、造价较高(孙宇, 2007; 王建军等, 2015; 崔崴和向茜, 2018), 在城市街道尺 度植被监测层面大规模推广应用较为困难。

本研究基于免费获取且已覆盖全国多数城市区 域的百度街景图像, 选取植被多样性及覆盖率较高 的泰安市区为案例区, 结合计算机监督分类方法提 取街道侧视视角绿植分布结果，验证计算机监督分 类提取植被信息的准确程度。提出适宜百度街景图 像的定量化植被格局, 通过案例区分析监测街道植 被的绿化格局。对比遥感图像植被信息提取结果, 分析两者的相关性及协同分析能力, 研究旨在为城 市规划与管理提供科学有效的方法和数据参考。

\section{1 材料和方法}

\section{1 研究区概况}

泰安市位于山东省中南部, 地处 $35.63^{\circ}-36.47^{\circ}$ $\mathrm{N}, 116.03^{\circ}-117.98^{\circ} \mathrm{E}$ 之间。案例区位于泰山脚下, 东西长约 $3.2 \mathrm{~km}$, 南北宽约 $1.9 \mathrm{~km}$, 属暖温带半湿 润大陆性季风气候, 植被类型丰富(刘含艳, 2007)。 参照OpenStreetMap 全球开放系统发布的数据结 果, 对案例区城市路网系统进行细化处理形成研究 路网。

\section{2 研究方法}

\subsection{1 数据来源与参数设定}

为精准分析案例区街道植被绿化格局, 基于 ArcGIS 10.6的随机选点功能模块在提取的道路矢 量图上随机生成 300 个研究样点。考虑到行人在平整 街道上的有效目视距离, 将任意两个随机样点之间 的最短距离阈值设置为 $30 \mathrm{~m}$, 剔除分布过近的样点, 最终得到研究样点 273 个, 并以样点位置的地理坐 标为参考网络抓取百度街景图像。图1以一个研究样 点为例显示了街道取景视图。通过使用百度街景图 像应用程序接口(API) 通过标准文本传输协议 (HTTP)请求发送的统一资源定位符(URL), 获取不 同方向及角度的百度街景图像。 

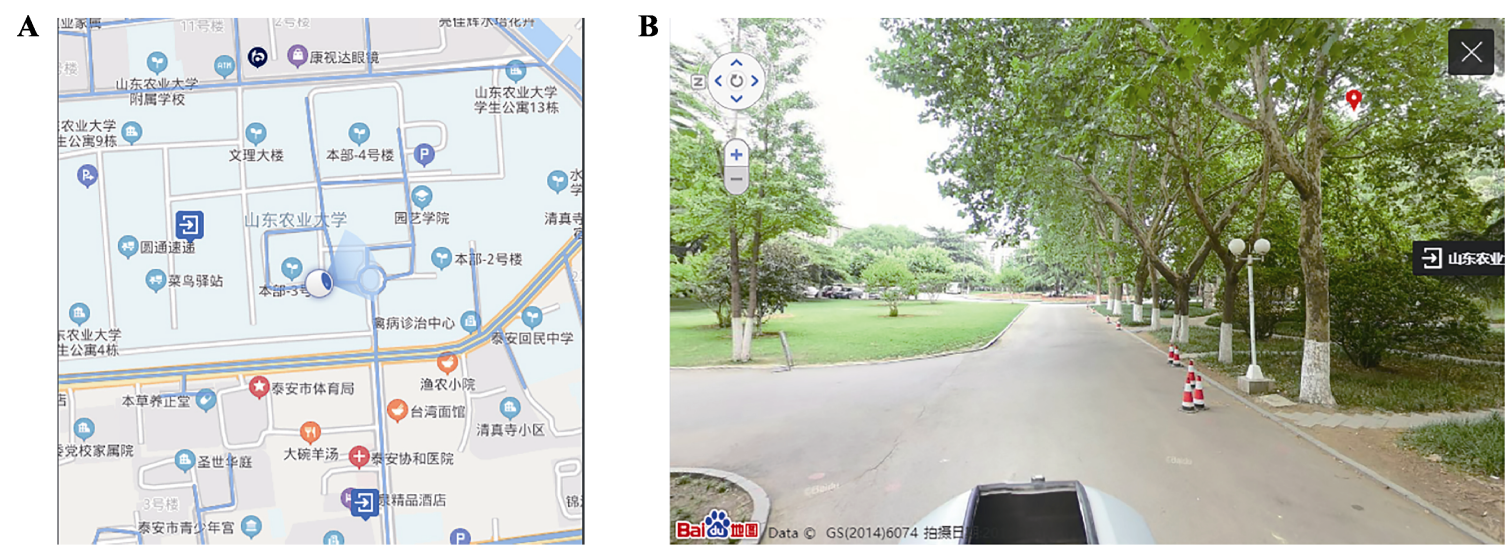

图1 研究样点街道视图实例。A, 样点位置。B, 样点对应的百度街景影像。

Fig. 1 An example of study site view. A, Location of a sample point. B, Baidu Street View image corresponding to the sample point.

在百度街景图像示例中, “width”和“height”确 定了所申请图像的输出大小, “location”标示了百度 街景图像的地理位置。URL中的字母“h”表示摄像机 的指南针方向(范围为 $0^{\circ}$ 到 $360^{\circ}$ ), “ $\mathrm{p}$ ”表示摄像机相 对于街景车辆的坚直方向角度。当“h”和“p”都设置 为“ 0 ”时, 意味着该图像是街景车辆以水平视角向 北行驶时获取的图像。图2是使用上述流程获取的百 度街景图像示例，拍摄时间为2016年6月12日。

为模拟行人的不同视角, 从 4 个水平方向和 3 个 坚直方向获取各街道研究样点的百度街景图像, 保 证能够覆盖每个样点的水平和坚直方向的球形环境, 在水平方向上将URL中的“h”分别设置为 $0 、 90 、 180$ 和270 (图3A); 在坚直方向上, 由于街景移动端顶 棚镜头基座的限制, 下载到的图像俯视角度受限, 得到图像的坚直角度范围为仰视 $+90^{\circ}$ 到俯视 $-20^{\circ}$ 。 因此, 将参数 “ $\mathrm{p}$ ” 设置为 $+60^{\circ} 、 0^{\circ}$ 以及最大俯视角度 $-20^{\circ}$ (图3B)。此外, 对比坚直方向上的图像发现, 坚直方向上 $0^{\circ}$ 和 $-20^{\circ}$ 的图像具有明显的重复绿色植 被部分, 可能导致绿色植被的监测结果偏高。在 ArcGIS 10.6中对比 $0^{\circ}$ 以及 $-20^{\circ}$ 图像确定 $-20^{\circ}$ 图像重 叠之外的区域为矢量掩膜范围, 利用Python语言编 写嵌入式处理程序统一批处理 273 幅 $-20^{\circ}$ 方向的图 像并输出为新的俯视角度图像。最终下载并处理存 储3 276张图像用于计算机监督分类及绿植分布监 测指数计算。

\subsection{2 数据处理}

1.2.2.1 百度街景图像分类 百度街景图像为三原 色(红绿蓝, RGB)模式, 没有对植被信息提取最为关 键的近红外波段信息, 本研究采用计算机监督分类 方法中鲁棒性强的最大似然法对百度街景图像进行

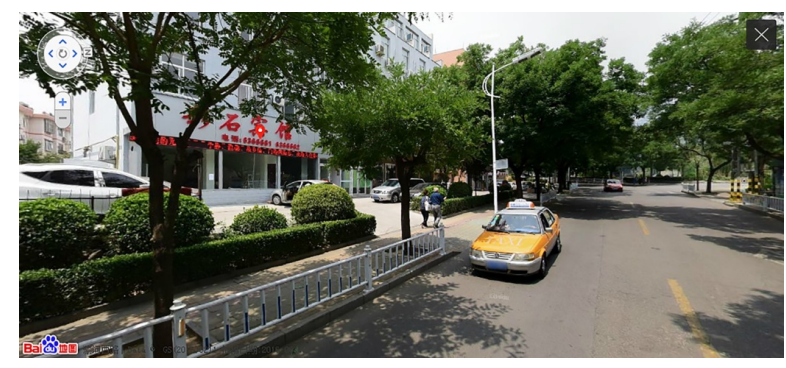

图2 百度街景图像示例。

Fig. 2 An example of Baidu Street View image.

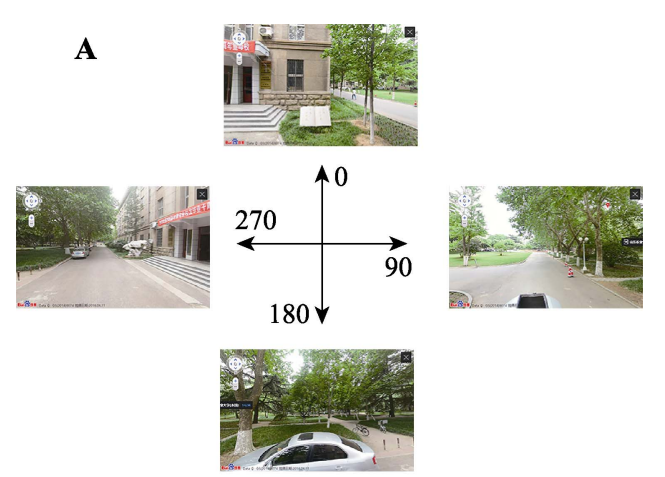

B

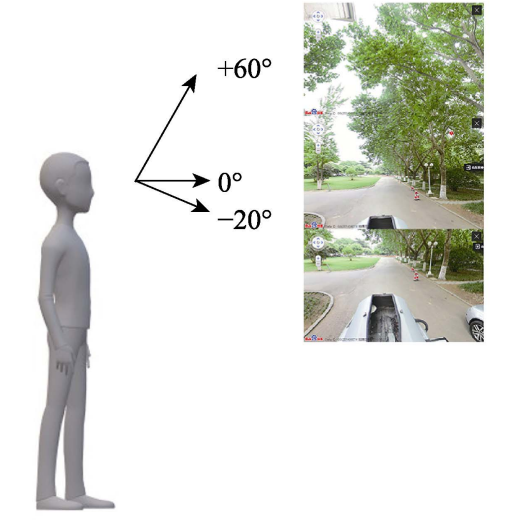

图3 街道样点水平方向 $(\mathbf{A})$ 和坚直视角 $(\mathrm{B})$ 上获取的百度街 景图像。

Fig. 3 Baidu Street View images in horizontal view (A) and vertical view (B). 
处理。为保证图像分类质量准确以计算后续的绿植 分布监测指数, 在图像分类处理前组织人员分组进 行了现场调查。根据案例区街道分布检查所有街道 研究样点, 并将所有百度街景图像与实地景象进行 比较, 记录可能错分或漏分的地物类型, 在室内对 比分析百度街景图像。在具体分类流程中, 将绿色 植被、阴影、树干、天空、建筑、路面、沥青等确 定为不同的分类类别以提高区分精度。然后根据不 同的感兴趣区域(ROI)利用最大似然法获得初始分 类图像, 之后将所有分类归并到植被区和非植被区 中。同时, 为衡量最大似然法的分类准确程度, 采用 人工目视解译检查植被识别结果, 得到人工分类图。

1.2.2.2 植被分布监测指数 为便于定量化分析案 例区街道样点的植被分布现状, 本研究采用研究样 点 4 个水平方向(图 3A)、每个水平方向上 3 个坚直 视角(图 3B)的街景图像计算案例区植被分布指数, 定 量分析行人视角的绿植分布情况。公式如下:

$$
B S V D I=\sum_{i=1}^{4} \sum_{j=1}^{3} \frac{\text { Area }_{g-i j}}{\text { Area }_{t-i j}} \times 100
$$

式中, BSVDI为百度街道植被分布指数, $i$ 代表 4 个水 平方向(东、南、西和北)的图像, $j$ 是每个方向 3 个
坚直视角 $\left(+60^{\circ} 、 0^{\circ}\right.$ 和 $\left.-20^{\circ}\right)$ 的图像。Area $a_{g-i j}$ 是百度街 景图像中的绿色植被像元总数, 其包含 4 个水平方 向的绿色像元总数, 以及每个水平方向上 3 个朝 向角度 $\left(+60^{\circ} 、 0^{\circ}\right.$ 和 $\left.-20^{\circ}\right)$ 图像的像元总数; Area $_{t-i j}$ 为 对应的百度街景图像的像元总数。在利用监督分类 方法获取各图像的绿植结果后, 基于上述公式计算 各街道研究样点的百度街道植被分布指数并空间化 显示。

\subsection{3 相关性计算}

对覆盖案例区的2016年6月的资源三号卫星拍 摄的多光谱影像(空间分辨率 $5.8 \mathrm{~m}$ )采用相同的处理 方法进行分类及处理, 将分类结果二值化为植被和 非植被两大类。考虑国内不同等级道路的宽度, 利 用缓冲区计算器(Buffer Creator)生成 $10 \mathrm{~m}$ (图4A)、 $20 \mathrm{~m}$ (图4B)和 $50 \mathrm{~m}$ (图4C)距离的缓冲区并分别与 遥感处理结果作求交(Intersect)处理, 得到 3 个缓冲 区内基于遥感影像提取的植被区域(图5), 将各样点 计算的百度街道植被分布指数与不同距离缓冲区内 植被覆被面积进行相关性计算, 验证侧视角度的百 度街道植被分布指数与卫星遥感沿天顶角向下提取 的植被冠层信息结果是否存在相关关系。
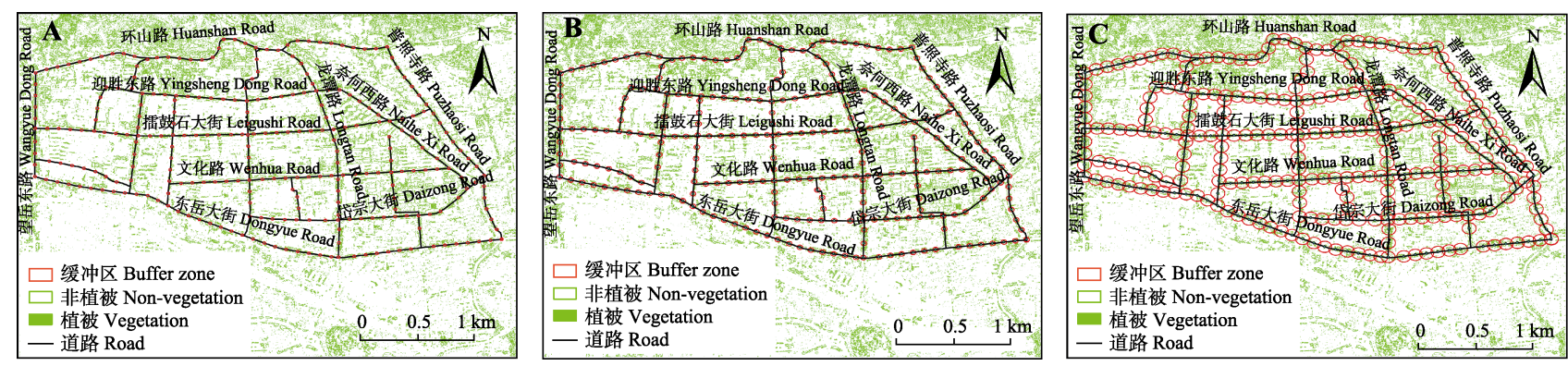

图4 泰安市区道路系统研究样点的缓冲区。A, $10 \mathrm{~m}$ 缓冲区。

Fig. 4 Buffer zones of the study sites in street system of Tai'an. A, $10 \mathrm{~m}$ buffer zones. B, $20 \mathrm{~m}$ buffer zones. C, $50 \mathrm{~m}$ buffer zones.
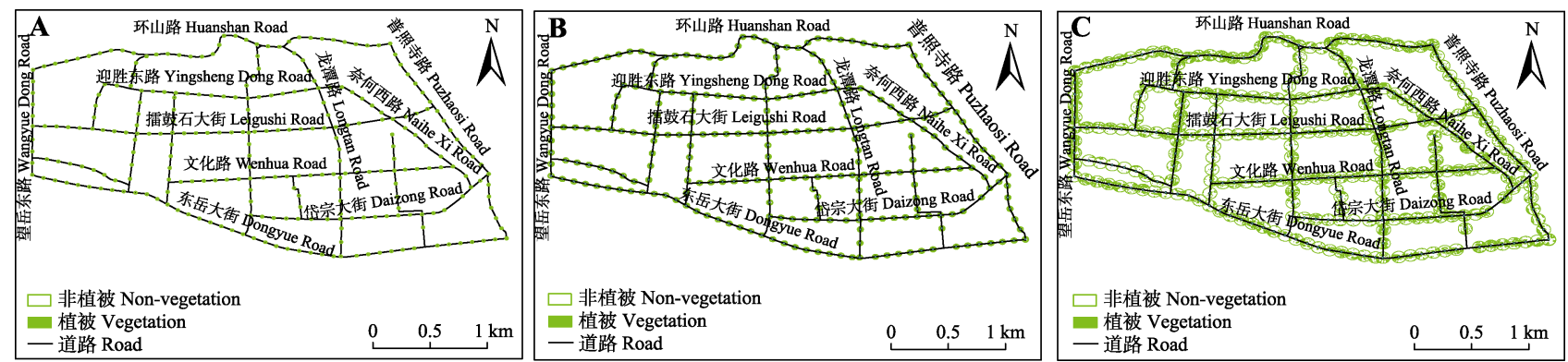

图5 求交处理后泰安市区道路系统缓冲区内的植被区域。A, $10 \mathrm{~m}$ 缓冲区。 $\mathbf{B}, 20 \mathrm{~m}$ 缓冲区。, $50 \mathrm{~m}$ 缓冲区。

Fig. 5 Vegetation area in the buffer area of street system of Tai' an after intersection processing. A, $10 \mathrm{~m}$ buffer zones. B, $20 \mathrm{~m}$ buffer zones. C, $50 \mathrm{~m}$ buffer zones. 


\section{2 研究结果}

\section{1 精度验证}

本研究采用最大似然法对抓取的3 276幅图像 进行计算机监督分类, 提取百度街景图像中的绿植 分布区域。图6为一个研究样点正北方向上坚直方向 不同角度的3幅图像。图6A是抓取的百度街景图像, 图6B是计算机监督分类结果, 图6C 是人工处理百 度街景图像的绿植提取结果。

对百度街道植被分布指数计算结果进行精度验 证, 随机选取 20 个研究样点, 对样点对应的百度街 景图像进行人工分类处理提取绿植信息, 结果参照 图6C, 计算植被分布指数。对比基于计算机监督分
类及人工分类结果计算的百度街道植被分布指数结 果并作散点图进行趋势拟合(图7)。基于计算机监督 分类的百度街道植被分布指数和基于人工分类百度 街景图像计算的百度街道植被分布指数之间的回归 关系，拟合曲线分布在 $1: 1.077$ 附近，总体回归系数 为 0.90 , 均方根误差为 14.08 。基于自动分类结果计 算的百度街道植被分布指数与人工处理结果具有较 强的一致性, 准确性较高。

\section{2 绿化格局分析}

案例区各样点的百度街道植被分布指数计算结 果如图8所示。点的大小代表百度街道植被分布指数 值的大小, 分级结果叠置于遥感影像分类图上。总 体而言，百度街道植被分布指数值较高的点多位于
$\mathbf{A}$
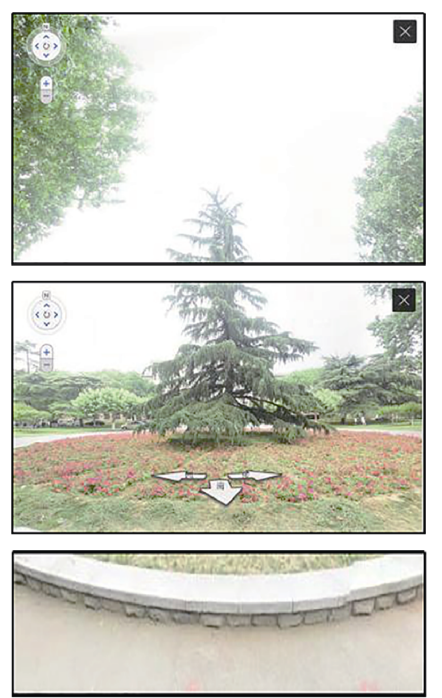
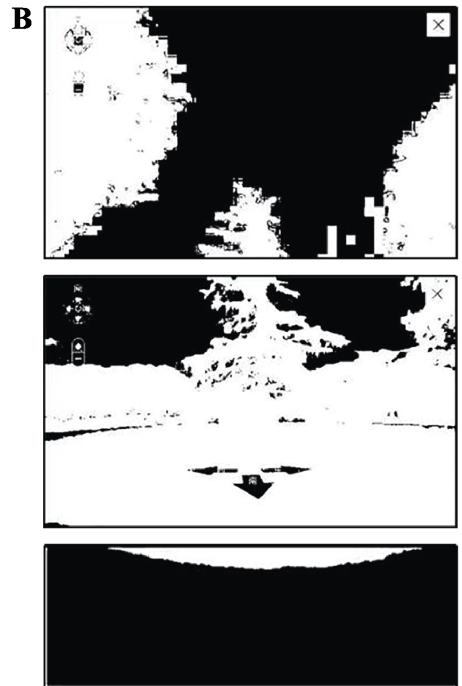
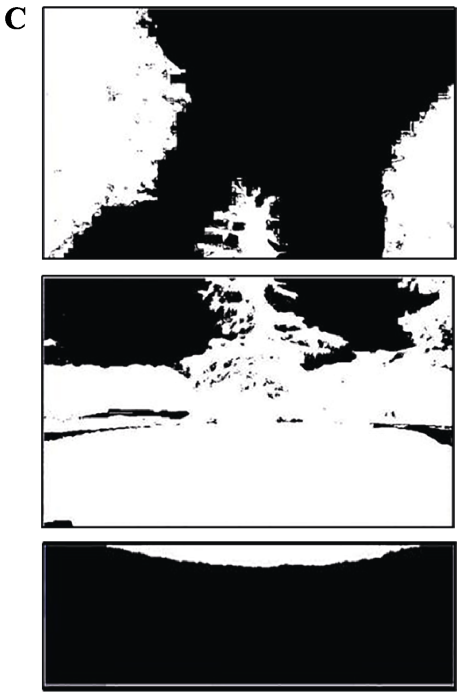

图6 泰安市百度街景提取结果实例。 $\mathrm{A}$, 原始百度街景图像。 $\mathrm{B}$, 最大似然方法处理结果。 $\mathbf{C}$, 人工处理结果。

Fig. 6 An example of classification result of Baidu Street View (BSV) image in Tai'an. A, Original BSV image. B, Classification results using Maximum Likelihood Classificer. C, Artificial classification results.

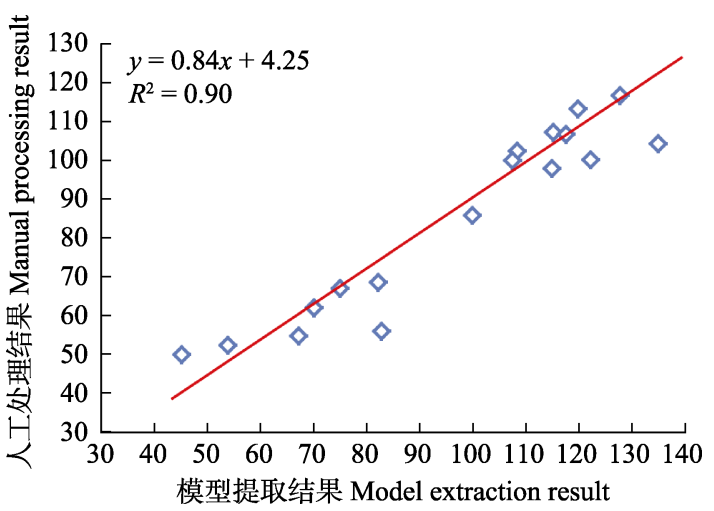

图7＼cjkstart监督分类计算泰安市百度街道植被分布指数与人工处 理结果散点图。

Fig. 7 Scatter plot of Baidu Street View Distribution Index $(B S V D I)$ results in Tai' an using maximum likelihood classification and artificial extraction method.

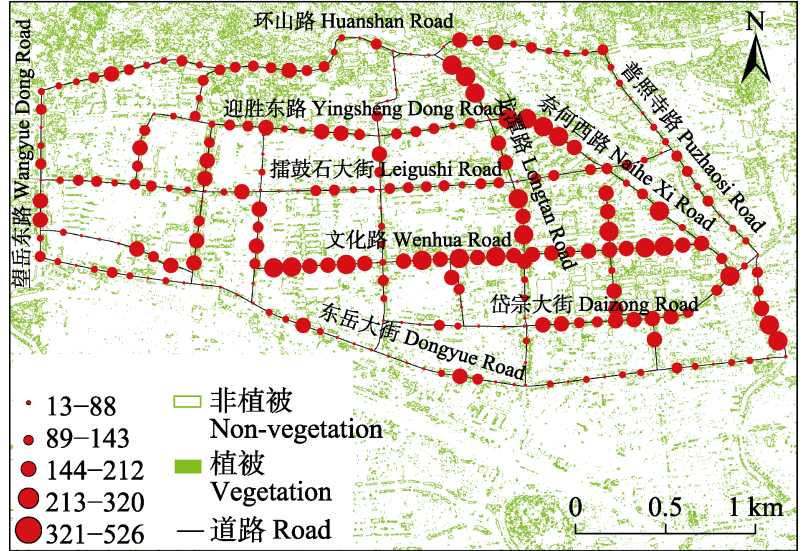

图8 泰安市案例区百度街道植被分布指数值分布格局。 Fig. 8 Baidu Street View Distribution Index (BSVDI) distributing pattern in the study area of Tai'an. 
案例区的中部和东南部, 在行人的观感体验上案例 区的中部和东北部比其他街道看起来更“绿”。

为进一步研究百度街道植被分布指数的空间分 布格局, 将案例区的道路系统按方向归为东西走向 和南北走向两类并编号(表1)。百度街道植被分布指 数值按自然断点法分为五级, 即一级为百度街道植 被分布指数大于等于 13 小于 88 , 标示为 $[13,88]$; 二 级为百度街道植被分布指数大于等于 89 小于 143 , 标示为 $[89,143)$; 以此类推得到三级 $[144,212)$; 四级 $[213,320)$ 及五级 $[321,526)($ 表1)。级数越高表明街道 绿植分布越多。

在 273 个研究样点中, 百度街道植被分布指数 最小值为 12.66 , 最大值达 526 , 案例区各街道绿植 分布差异明显。对比图8及表1, 在东西方向的7条街 道中, 文化路百度街道植被分布指数较大, 有 14 个 和 8 个样点位于四级及五级百度街道植被分布指数 区，分别占街道样点总数( 25 个)的 $56 \%$ 和 $32 \%$, 表明 该路段绿植分布较广, 在行人视觉感受中目视范围
内更绿。相比之下, 其他6条均无五级百度街道植被 分布指数样点。东岳大街有 21 个 $(50 \%)$ 和 15 个 (36\%) 样点位于百度街道植被分布指数一级及二级区间 (表1), 说明该路段绿植侧视覆被范围不大, 需在未 来城市规划中加以重点关注。后续分析发现文化路 修成时间达 10 年以上，绿植栽种时间较长，植被生 长茂盛; 东岳大街建成时间较短(2010年改造完成), 绿植移栽时间不长, 因此百度街道植被分布指数普 遍较低。在南北方向上, 普照寺路、龙潭路及奈何 西路等老城区街道绿植高值样点较多, 其余街道多 集中于低值区(表1), 宜施加措施提高绿植侧视覆 盖率。

\section{3 相关性分析}

表2显示了在 $10 、 20 、 50 \mathrm{~m}$ 缓冲距离下的百度 街道植被分布指数值与植被覆盖面积(图5)之间的 相关系数。分析发现百度街道植被分布指数值与样 点不同缓冲区距离范围内的植被覆盖面积具有较强 的相关性。其中 $10 \mathrm{~m}$ 缓冲区范围内植被覆被面积与

表1 泰安市研究样点百度街道植被分布指数 $(B S V D I)$ 分级统计结果

Table 1 Baidu Street View Distribution Index (BSVDI) gradation results of the study sites

\begin{tabular}{|c|c|c|c|c|c|c|c|c|}
\hline \multirow{2}{*}{$\begin{array}{l}\text { 编号 } \\
\text { ID }\end{array}$} & \multirow{2}{*}{$\begin{array}{l}\text { 走向 } \\
\text { Orientation }\end{array}$} & \multirow{2}{*}{$\begin{array}{l}\text { 街道名称 } \\
\text { Name of street }\end{array}$} & \multicolumn{5}{|c|}{$B S V D I$} & \multirow{2}{*}{$\begin{array}{l}\text { 汇总 } \\
\text { Sum }\end{array}$} \\
\hline & & & $\begin{array}{c}\text { 一级 } \\
\text { First class } \\
{[13,88)}\end{array}$ & $\begin{array}{c}\text { 二级 } \\
\text { Second class } \\
{[89,143)}\end{array}$ & $\begin{array}{c}\text { 三级 } \\
\text { Third class } \\
{[144,212)}\end{array}$ & $\begin{array}{c}\text { 四级 } \\
\text { Fourth class } \\
{[213,320)}\end{array}$ & $\begin{array}{c}\text { 五级 } \\
\text { Fifth class } \\
{[321,526)}\end{array}$ & \\
\hline 0 & 东-西 East-West & 环山路 Huanshan Road & 5 & 13 & 12 & 4 & 0 & 34 \\
\hline 1 & 东-西 East-West & 迎胜东路 Yingsheng Dong Road & 3 & 5 & 8 & 3 & 0 & 19 \\
\hline 2 & 东-西 East-West & 擂鼓石大街 Leigushi Road & 8 & 9 & 17 & 1 & 0 & 35 \\
\hline 3 & 东-西 East-West & 文化路 Wenhua Road & 0 & 1 & 2 & 14 & 8 & 25 \\
\hline 4 & 东-西 East-West & 御碑楼南街 Yubeilou Nan Road & 3 & 1 & 1 & 2 & 0 & 7 \\
\hline 5 & 东-西 East-West & 岱宗大街 Daizong Road & 7 & 3 & 5 & 5 & 1 & 21 \\
\hline 6 & 东-西 East-West & 东岳大街 Dongyue Road & 21 & 15 & 4 & 2 & 0 & 42 \\
\hline 7 & 南-北 South-North & 傲来峰路 Aolaifeng Road & 4 & 3 & 3 & 1 & 0 & 11 \\
\hline 8 & 南-北 South-North & 附中西路 Fuzhong Xi Road & 0 & 0 & 2 & 1 & 0 & 3 \\
\hline 9 & 南-北 South-North & 校场街路 Jiaochangjie Road & 0 & 1 & 0 & 5 & 1 & 7 \\
\hline 10 & 南-北 South-North & 科山路 Keshan Road & 2 & 1 & 1 & 2 & 0 & 6 \\
\hline 11 & 南-北 South-North & 龙潭路 Longtan Road & 3 & 3 & 0 & 4 & 5 & 15 \\
\hline 12 & 南-北 South-North & 奈河西路 Naihe Xi Road & 1 & 2 & 2 & 1 & 5 & 11 \\
\hline 13 & 南-北 South-North & 普照寺路 Puzhaosi Road & 3 & 7 & 5 & 1 & 2 & 18 \\
\hline 14 & 南-北 South-North & 望岳东路 Wangyue Dong Road & 1 & 2 & 2 & 2 & 0 & 7 \\
\hline 15 & 南-北 South-North & 迎胜路 Yingsheng Road & 1 & 0 & 2 & 4 & 0 & 7 \\
\hline 16 & 南-北 South-North & 中心医院西路 Zhongxinyiyuan Xi Road & 1 & 0 & 1 & 1 & 0 & 3 \\
\hline \multirow[t]{2}{*}{17} & 南-北 South-North & 东尊西路 Dongzun Xi Road & 0 & 1 & 1 & 0 & 0 & 2 \\
\hline & 汇总 Sum & & 63 & 67 & 68 & 53 & 22 & 273 \\
\hline
\end{tabular}


表2 泰安市百度街道植被分布指数与植被覆盖面积相关性分析

Table 2 Correlation analysis between Baidu Street View Distribution Index $(B S V D I)$ and vegetation coverage area in Tai' an

\begin{tabular}{ccc}
\hline $\begin{array}{c}\text { 缓冲距离 } \\
\text { Buffer distance }(\mathrm{m})\end{array}$ & $\begin{array}{c}\text { Pearson相关系数 } \\
\text { Pearson correlation } \\
\text { coefficients }\end{array}$ & $\begin{array}{c}\text { 样本点数量 } \\
\text { Number of sample } \\
\text { points }\end{array}$ \\
\hline 10 & $0.76^{* *}$ & 273 \\
20 & $0.63^{* *}$ & \\
50 & $0.49^{* *}$ & \\
\hline
\end{tabular}

$* *, p<0.005$ 。

百度街道植被分布指数相关性达 0.76 , 呈显著正相 关关系。相比 $10 \mathrm{~m}$ 道路距离下的高相关性, 20、50 m 道路距离内的相关性渐弱, 主要原因在于人眼距离 样点越近，观察到的绿色植被面积越大，感受到的 绿色部分越多, 反之越小。基于遥感图像的结果则 不会出现此差异性。实际分析发现, 在某些百度街 道植被分布指数值较高的样点，其分布与植被覆盖 度较高的区域不完全吻合，原因在于侧视角度的百 度街道植被分布指数与卫星遥感沿天顶角向下提取 的植被冠层信息存在差异。通过实地验证发现，这 些采样点大多位于有遮挡物的道路中，人的视野范 围难以覆盖到远离街道或被建筑物阻挡的绿地。虽 然二者相关性较高, 但从遥感图像上观测到的大范 围的植被并不完全意味着在街道上有更高的百度街 道植被分布指数，两者在有阻挡或多层次绿化格局 区域有明显差异。

\section{3 研究结论}

本研究利用百度街景图像进行街道植被信息提 取与监测, 提出一种基于百度街景图像的植被分布 指数用于量化街道植被分布情况并监测分布格局。 研究结果表明百度街景图像是评价城市街道绿化的 一种有效的信息源, 基于百度街景图像可快速高效 地监测城市街道植被分布格局。通过使用百度API 解析URL以抓取研究样点对应的百度街景图像, 无 需手动采集; 对百度街景图像进行计算机监督分类, 提取绿色植物覆被区域, 整个过程自动化程度较 高。百度街景已基本覆盖全国范围的城市区域, 并 将继续向农村区域覆盖, 研究具有较大的应用前 景。由于目前遥感图像大多监测俯视视角的植被覆 盖度, 而百度街景能够从行人的角度监测城市街道 景观, 百度街道植被分布指数值可作为遥感图像提 取结果的辅助信息共同构建城市街道立体分析网络, 更准确地量化评价城市绿化现状。目前相关研究多
以问卷调查形式对行人视角街道绿化情况进行评估, 可设计完善的城市景观美学调查问卷评估行人对城 市街道绿化状况的满意程度, 将本研究提出的指数 结果与问卷调查的街道绿化的评估结果进行对比。

受到百度街景图像获取的影响, 本研究仍有限 制因素需加以克服。目前可获取的街道信息均为静态 图像, 计算得到的百度街道植被分布指数值代表图 像拍摄时间的城市绿化状况，而街道绿色植物均处 于动态变化状态。未来如何利用百度API获取多时相 的百度街景图像以进行城市街道植被的动态变化分 析是需要解决的问题。此外，对影响百度街道植被分 布指数分析的因素, 如季节变化、绿化及建筑物阴 影的分布，以及街道宽度及地形起伏等因素都会对 研究结果产生影响, 如何克服这些影响因素, 扩大本 研究指数的应用范围亦是下一步研究的重点方向。

\section{参考文献}

Aoki Y, Yasuoka Y, Naito M (1985). Assessing the impression of street-side greenery. Landscape Research, 10, 9-13.

Bai Y, Wang XY, Jiang HM, Liu SD (2013). Progress of urban heat island effect. Journal of Meteorology and Environment, 29(2), 101-106. [白杨, 王晓云, 姜海梅, 刘寿东 (2013). 城市热岛效应研究进展. 气象与环境学报, 29(2), 101-106.]

$\mathrm{Bu} F$, Shi YL (2017). The comparison of urban tree crown extraction based on airborne LiDAR elevation difference and high resolution imagery. Remote Sensing Technology and Application, 32, 875-882. [卜帆, 石玉立 (2017). 机载 LiDAR高差和高分影像的城市树冠提取比较. 遥感技 术与应用, 32, 875-882.]

Camacho-Cervantes M, Schondube JE, Castillo A, MacGregorFors I (2014). How do people perceive urban trees? Assessing likes and dislikes in relation to the trees of a city. Urban Ecosystems, 17, 761-773.

Chen QN (1984). The use of Tianjin colour infrared film in the study of the relationship between vegetation and air pollution. Acta Phytoecologica et Geobotanica Sinica, 8, 112-122. [陈庆男 (1984). 天津市彩色红外相片在研究 植被与大气污染关系中的应用. 植物生态学与地植物 学丛刊, 8, 112-122.]

Cui W, Xiang Q (2018). Design and study of high precision laser rangefinder. Laser Journal, 39(7), 46-49. [崔嵗, 向 茜 (2018). 高精度激光测距仪的设计与研究. 激光杂 志, 39(7), 46-49.]

Di SC, Li ZL, Tang RL, Pan XY, Liu HL, Niu Y (2019). Urban green space classification and water consumption analysis with remote-sensing technology: a case study in Beijing, China. International Journal of Remote Sensing, 40, 
1909-1929.

Downs RM, Stea D, Meining DW (1977). Maps in Minds: Reflections on Cognitive Mapping. Harper and Row, New York.

Golombek Y, Marshall WE (2019). Use of aerial LiDAR in measuring streetscape and street trees. Transportation Research Record, 2673(4), 125-135.

Heo HK, Lee DK, Park JH, Thorne JH (2019). Estimating the heights and diameters at breast height of trees in an urban park and along a street using mobile LiDAR. Landscape and Ecological Engineering, 15, 253-263.

Klemm W, Heusinkveld BG, Lenzholzer S, van Hove B (2015). Street greenery and its physical and psychological impact on thermal comfort. Landscape and Urban Planning, 138, 87-98.

Li J, Zhao JJ, Chen SS, Chen CD, Zhang QX (2017). Species composition of urban alien plants in Xiamen, China. Ecology and Environmnetal Sciences, 26, 20-26. [李净, 赵娟娟, 陈珊珊, 陈春娣, 张启翔 (2017). 厦门市城市 外来植物的种类构成. 生态环境学报, 26, 20-26.]

Li W (2007). The Application of CITYgreen in Urban Green-land Ecological Benefits Evaluation. Master degree dissertation, Beijing Forestry University, Beijing. 1-3. [李 薇 (2007). CITYgreen软件在城市绿地生态效益评价中 的应用一以奥林匹克森林公园规划方案为例. 硕士 学位论文, 北京林业大学, 北京. 1-3.]

Li Z, Sun RH, Zhang JC, Zhang C (2017). Temporal-spatial analysis of vegetation coverage dynamics in BeijingTianjin-Hebei metropolitan regions. Acta Ecologica Sin$i c a, 37,7418-7426$. [李卓, 孙然好, 张继超, 张羽 (2017). 京津冀城市群地区植被覆盖动态变化时空分析. 生态学报, 37, 7418-7426.]

Liu HY (2007). The Current Situation, Problems and Path Selection of Eco-city Construction in China: a Case Study of Tai'an City, Shandong Province. Master degree dissertation, Hubei University, Wuhan. 17. [刘含艳 (2007). 我 国生态城市建设的现状、问题及路径选择一以山东省 泰安市为例. 硕士学位论文, 湖北大学, 武汉. 17.]

Ren XH, Tian HX, Liu Y (2006). Preliminary study on spatial difference of the vegetation coverage adjusting to climate. Journal of Yunnan Agricultural University, 21, 806-810. [任学慧, 田红霞, 刘瑜 (2006). 植被覆盖调节气候空 间差异性的初步研究. 云南农业大学学报, 21, 806-810.]

Su Y, Bao Y (2018). Spatial-temporal characteristics of urban heat island effect in Hanzhong City in recent 20 years based on mono-window algorithm. Journal of Northwest Forestry University, 33(4), 183-192. [苏嫄, 包玉 (2018). 基于单窗算法的汉中市近 20 年城市热岛效应时空特征. 西北林学院学报, 33(4), 183-192.]

Sun P (2006). Try to construct a pattern of sustainable development for resource-oriented cities based on people-centered development. Planners, 22(4), 5-6. [孙平 (2006). 以人为 本努力构建资源型城市可持续发展模式. 规划师, 22(4), 5-6.]

Sun Y (2007). Three-dimensional Terrain Construction of Robot and Obstacle Detection in Grass Based on LiDAR. Master degree dissertation, Zhejiang University, Hangzhou. [孙宇 (2007). 基于激光雷达的机器人三维地形 构建和草丛中障碍物检测. 硕士学位论文, 浙江大学, 杭州.]

van Dillen SME, de Vries S, Groenewegen PP, Spreeuwenberg $P$ (2012). Greenspace in urban neighbourhoods and residents' health: adding quality to quantity. Journal of Epidemiology \& Community Health, 66, e8. DOI:10.1136/ jech.2009.104695.

Wang FJ (2004). Guided by the scientific concept of development, improve the level of urban landscaping. Beijing Garden, 20(4), 3-11. [王凤江 (2004). 以科学的发展观 为指导, 提升城市园林绿化水平一关于充分发挥园 林绿化作用, 实现城市可持续发展的研究与思考. 北京 园林, 20(4), 3-11.]

Wang G, Zhang QP, Xiao RB, Guan DS (2017). Urban thermal island regulated by green spaces-A case study of Guangzhou. Ecological Science, 36(1), 170-176. [王刚, 张秋平，肖荣波，管东生 (2017). 城市绿地对热岛效应 的调控功能研究——广州为例. 生态科学, 36(1), 170-176.]

Wang J, Yang HQ, Feng ZK (2013). Tridimensional green biomass measurement for trees using 3-D laser scanning. Transactions of the Chinese Society for Agricultural Machinery, 44(8), 229-233. [王佳, 杨慧乔, 冯仲科 (2013). 基于三维激光扫描的树木三维绿量测定. 农业机械学 报, 44(8), 229-233.]

Wang J, Zhou WQ, Xu KP, Yan JL (2017). Spatiotemporal pattern of vegetation cover and its relationship with urbanization in Beijing-Tianjin-Hebei megaregion from 2000 to 2010. Acta Ecologica Sinica, 37, 7019-7029. [王 静, 周伟奇, 许开鹏, 颜景理 (2017). 京津冀地区城市 化对植被覆盖度及景观格局的影响. 生态学报, 37 , 7019-7029.]

Wang JJ, Li XL, Xu TL, Li DX, Huo WX (2015). Comparison of impacts of control errors and measurement errors of working parameters on accuracies of point cloud products from airborne LiDAR. Chinese Journal of Lasers, 42(7), 202-210. [王建军, 李小路, 许同乐, 李东兴霍文骁 (2015). 机载LiDAR中工作参数的控制误差和测量误差 对点云产品精度的影响机理及其比较. 中国激光, 42(7), 202-210.]

Wang SY, Zhang ZX, Zhou QB, Wang CY (2002). Study on spatial-temporal features of land use/land cover change based on technologies of RS and GIS. Journal of Remote Sensing, 6, 223-228. [王思远, 张增祥, 周全斌, 王长有 (2002). 基于遥感与GIS技术的土地利用时空特征研究.

www.plant-ecology.com 
遥感学报, 6, 223-228.]

Wang ZH, Li JB (2006). Capacity of dust uptake by leaf surface of Euonymus japonicus Thunb. and the morphology of captured particle in air polluted city. Ecology and Environment, 15, 327-330. [王赞红, 李纪标 (2006). 城市街 道常绿灌木植物叶片滞尘能力及滞尘颗粒物形态. 生 态环境, 15, 327-330.]

Wei D, Li L, Ni XL (2017). Evaluation of urban forest ecosystem service function in Yinchuan botanical garden. Xiandai Horticulture, (21), 12-15. [魏冬, 李龙, 倪细炉 (2017). 银川植物园城市森林生态系统服务功能评价. 现代园艺, (21), 12-15.]

Wu JS, Yuan T, Wang T (2017). Preliminary theory of urban landscape esthetics based on three-dimensional landscape indicators. Acta Ecologica Sinica, 37, 4519-4528. [吴健 生, 袁甜, 王肜 (2017). 基于三维景观指数的城市景观 美学特征定量表达一以深圳市为例. 生态学报, 37, 4519-4528.]

Yang CB, He XY, Wang RH, Yan FQ, Yu LX, Bu K, Yang JC, Chang LP, Zhang SW (2017). The effect of urban green spaces on the urban thermal environment and its seasonal variations. Forests, 8, 153. DOI: 10.3390/88050153.

Yang ZQ, Chen BZ, Zha TS, Jia X (2016). Relationship between photochemical reflectance index with multianglehyper-spectrum and light use efficiency in urban green-land ecosystems. Chinese Journal of Plant Ecology, 40, 1077-1089. [杨志青, 陈报章, 查天山, 贾昕 (2016). 城市绿地生态系统多角度高光谱光化学反射植被指数 与光能利用率的关系. 植物生态学报, 40, 1077-1089.]

Zhang JH (2017). Visibility Assessment of Urban Street-level Greenery Using Street View Imagery and LiDAR. Master degree dissertation, University of Chinese Academy of Sciences, Beijing. 1-2. [张佳晖 (2017). 基于街景和 LiDAR的行道树绿视面积计算研究. 硕士学位论文, 中 国科学院大学, 北京. 1-2.]

Zhang JH, Meng QY, Sun YX, Sun ZH, Zhang LL (2017). Study on urban green view index. Journal of Geo-Information Science, 19, 838-845. [张佳晖, 孟庆岩, 孙云晓, 孙震 辉, 张琳琳 (2017). 城市行道树绿视量指数研究. 地球 信息科学学报, 19, 838-845.]

特邀编委: 戴君虎 编辑: 赵 航 